\title{
PERANCANGAN SISTEM TRANSAKSI PEMESANAN PERUSAHAAN JASA SABLON
}

\author{
Rifa Nurafifah Syabaniah ${ }^{1}$, Yusti Farlina ${ }^{2}$, Nurlaelasari ${ }^{3}$ \\ ${ }^{1}$ AMIK BSI Tasikmalaya \\ e-mail: rifa.rrf@bsi.ac.id \\ 2 AMIK BSI Sukabumi \\ e-mail: yusti.yfa@bsi.ac.id \\ ${ }^{3}$ AMIK BSI Sukabumi \\ e-mail: nurlaelasari@gmail.com
}

\begin{abstract}
Abstrak
Mugie Screen Printing merupakan suatu perusahaan sablon yang bergerak dibidang jasa. Berdasarkan dari penelitian, perusahaan ini memiliki masalah dalam pemesanan dan transaksi sablon karena masih dilakukan secara konvensional sehingga kerap terjadi kesalahan dalam perhitungan transaksi dan belum adanya katalog bagi konsumen sehingga proses pemesanan sering terhambat. Oleh karena itu dibuatkanlah Rancangan Aplikasi Sistem Katalog Dan Transaksi Perusahaan Jasa Sablon berdasarkan hasil wawancara dan studi pustaka. sehingga Terbentuklah sistem terkomputerisasi yang menggantikan sistem sebelumnya yang masih manual. Dengan dibuatkan sistem katalog dan transaksi ini mecahkan permasalahan yang ada diperusahaan ini, serta dengan sistem ini dapat mencapai kegiatan transaksi lebih mudah, efektif dan cepat. Lalu setiap proses lebih teorganisir dan mengurangi kesalahan dalam pencatatan ataupun dalam perhitungannya.
\end{abstract}

\section{Kata Kunci: Perancangan Sistem Transaksi pemesanan}

\section{Abstract}

Mugie Screen Printing is a screen printing company engaged in services. Based on the research, this company has problems in ordering and screen printing because it is still done conventionally so often error in the calculation of transactions and the absence of catalogs for consumers so that the ordering process is often hampered. Therefore made the final task of the Cataloging System and Transaction Company Sablon Services conducted by interview and literature study. So Formed a computerized system that replaces the previous system that is still manual. With this catalog and transaction system made solve the problems that exist in this company, and with this system can achieve transaction activity easier, effective and fast. Then each process is more organized and reduces errors in recording or in its calculations.

Keywords: Designing of Catalog System transaction 


\section{Pendahuluan}

\subsection{Latar Belakang Masalah}

Sablon merupakan sebuah teknik untuk mencetak tinta atau cat diatas bahan (kain) dengan bentuk yang kita kehendaki. Dengan bantuan screen sablon dan rakel dalam proses pengerjannya. Teknik sablon memiliki keunggulan tersendiri, sekali pengerjaan dapat mencetak dalam jumlah yang relatif banyak, hasil cetakan relatif stabil, dapat menghasilkan beberapa efek menarik dan fleksibel di aneka jenis permukaan bahan. Bisnis ini termasuk bisnis yang menjanjikan untuk perposfek kedepannya Menurut (Falahi, Alimart, Saputra, Ayunasta, \& Simatupang, 2015).

masalah selanjutnya dalam pencatatan transaksi pemesanan pembuatan kaos sablon karena masih konvensional mengakibatkan lambatnya jalan proses pemesanan pada Mugie Screen Printing. setiap pemesanan harus mencatat data dan menghitung total nominalnya dari semua pemesanan yang diberikan secara manual sehingga kekeliruan penghitungan sering terjadi.

Dengan adanya masalah tersebut dibuat judul "perancangan Sistem Transaksi Pemesanan Perusahaan Jasa Sablon" dengan sistem yang terkomputerisasi ini diharapkan dapat mempermudah konsumen dan perusahaan dalam bertransaksi dan membuat proses lebih efektif dan cepat.

\subsection{Metode Penelitian}

Untuk mengetahui informasi serta datadata guna tersusunnya Hasil Penelitian ini maka digunakan metode, yaitu:

a. Metode Observasi

Data dikumpulkan langsung dengan cara melakukan pengamatan langsung di mugie screen printing dengan object yang diteliti.

b. Metode Wawancara

Pengumpulan data dilakukan dengan cara bertanya langsung pada pegawai atau pemilik usaha cara ini dimaksudkan untuk kemudahan mendapatkan data.

c. Metode Pustaka

Metode pengumpulan data dilakukan dengan mencari informasi dari buku yang berkaitan.

\subsection{Ruang Lingkup}

Berdasarkan dari permasalahan pada Mugie Screen Printing dibuat suatu perancangan sistem pelayanan pemesanan yang lebih efektif dan cepat, agar tidak menyimpang dari permasalahan maka dibuat batasan masalah yaitu Proses pemilihan pesanan dari katalog bahan, warna, desain kaos, gambar kaos dan katalog kaos yang telah jadi desain, serta proses pencatatan transaksi pemesanan dengan sistem.

\section{Tinjauan Perusahaan \\ 2.1 Sejarah Mugie Screen Printing}

Mugie Screen Printing berada dijalan Pelabuhan II km $8 \mathrm{Kp}$, Tegallega Kidul Kecamatan Lembursitu Kelurahan Lembursitu Kota Sukabumi. Asal mula berdirinya usaha jasa sablon ini terjadi dari ketidak sengajaan obrolan pemilik dengan saudaranya, yang waktu itu sedang mengobrolkan mengenai orderan kaos sablon yang sedang diterima saudaranya di tempat usaha dia bekerja, lalu pemilik membicarakan mengenai membuka usaha bersama dan saudara menyetujuinya.

Maka terbentuk Mugie Screen Printing pada tanggal 12 September 2016, Meski belum lama berkiprah dalam bisnis ini, usaha jasa sablon ini tidak sepi peminat, karena kebutuhan akan pakaian yang dihasilkan dengan secara manual masih dicari oleh pemilik-pemilik toko seperti distro.

\section{Hasil dan Pembahasan}

\subsection{Prosedur Sistem}

Prosedur sistem pemesanan dan pencatatan pada Mugie Screen Printing.

a. Prosuder pendaftaran konsumen

Admin memberikan formulir pendaftaran dan katalog ke konsumen untuk syarat pendataan konsumen sehingga memudahkan untuk proses pemesanan selanjutnya.

b. Prosedur Transaksi Pemesanan

Konsumen memberikan formulir perndaftaran dan data pesanan yang telah diisi ke admin yang nantinya data konsumen tersebut dimasukan ke file konsumen dan data pesanan dimasukan ke file transaksi.

c. Prosedur proses laporan transaksi data laporan diambil dari file transaksi yang nantinya di laporkan ke pemilik. 


\subsection{Diagram Konteks Sistem}
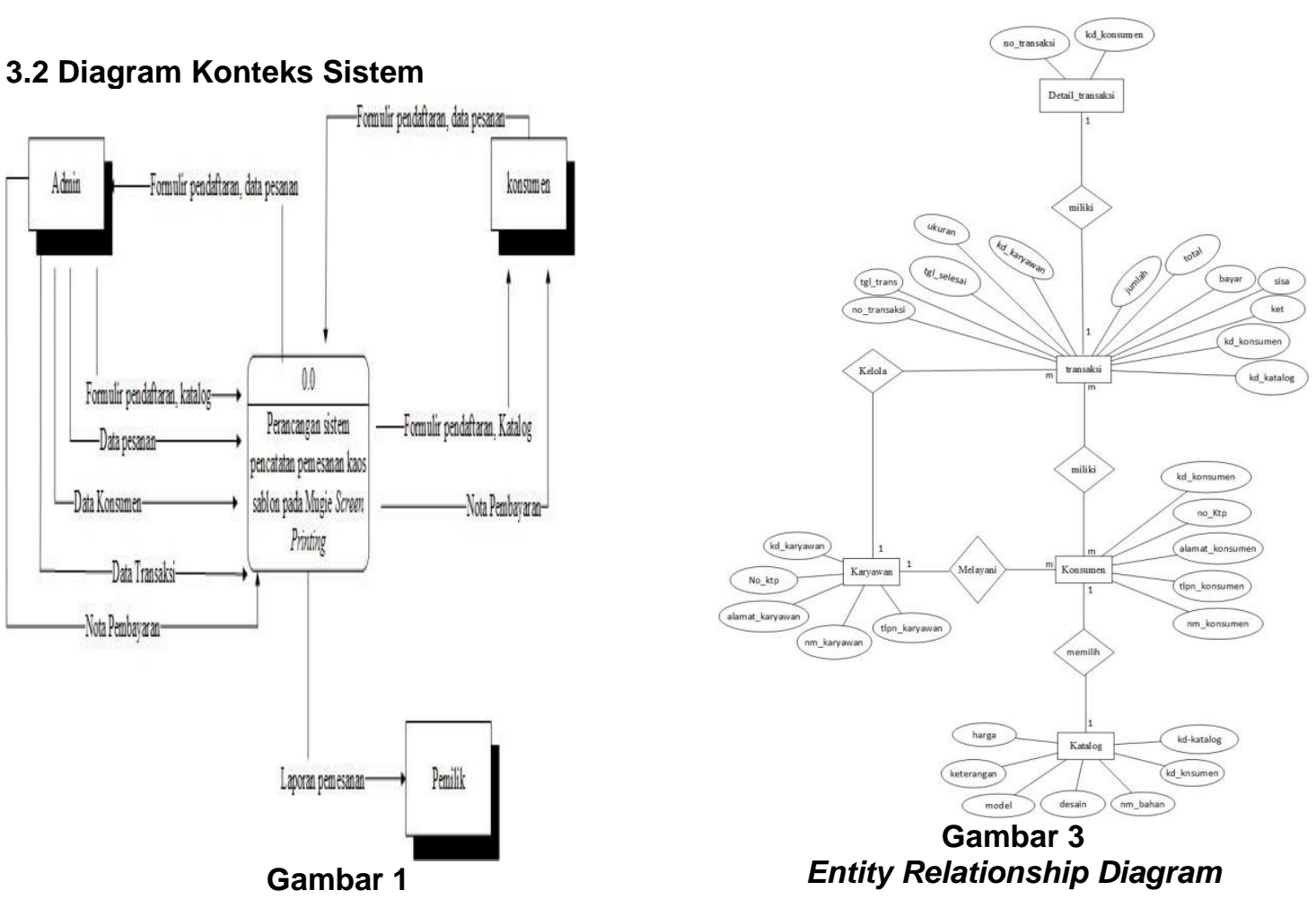

Diagram konteks Sistem

\subsection{Diagram Nol Sistem}

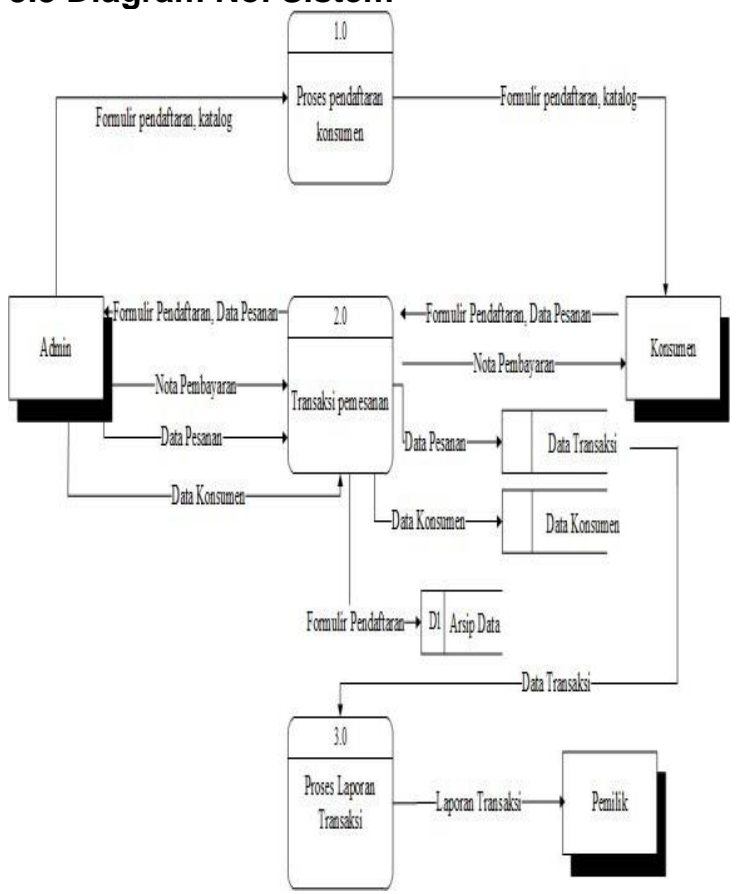

Gambar 2

Diagram Nol Sistem

3.4 Entity Relationship Diagram 
3.5 Logical Record Structure

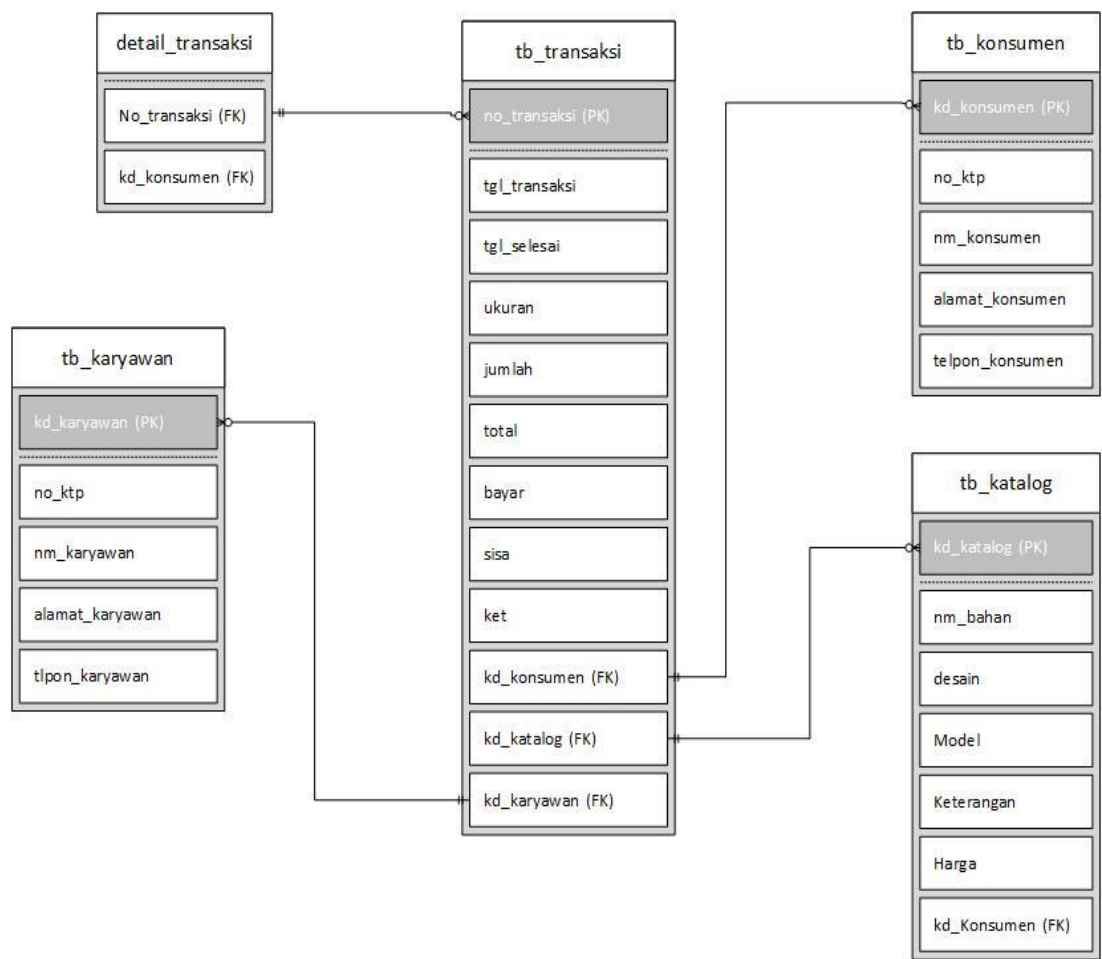

Gambar 4

3.6 Spesifikasi File

Logical Record Structure

a. File Karyawan

Nama Tabel : File Karyawan

Akronim : Karyawan

Fungsi : Untuk menyimpan data Karywan

Organisasi : Indexed Sequental

Akses File : Random

Primary Key : kd_karyawan

Media : Hard Disk

Record Size : 87 Karakter

Software : Microsoft Acces 2013

b. Spesifikasi File Konsumen

Nama Tabe : File konsumen

Akronim : Konsumen

Fungsi : Untuk memasukan data konsumen

Tipe : File Master

Organisasi : Indexed Sequental

Akses File : Random

Primary Key : kd_konsumen

Media : Hard Disk

Record Size : 85 Karakter

Software : Microsoft Acces 2013

c. Spesifikasi File Katalog

Nama Tabel : File Katalog

Akronim : Konsumen

Fungsi : Untuk melihat daftar model produksi

Tipe : File Master

Organisasi : Indexed Sequental 


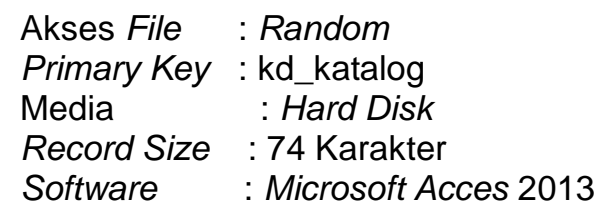

d. Spesifikasi File Transaksi

Nama Tabel : file Transaksi

Akronim : transaksi

Fungsi : Untuk mentimpan data transaksi

Organisasi : Indexed Sequental

Akses File : Random

Primary Key : kd_transaksi

Media : Hard Disk

Record Size : 103 Karakter

Software : Microsoft Acces 2013

\subsection{Spesifikasi Program}

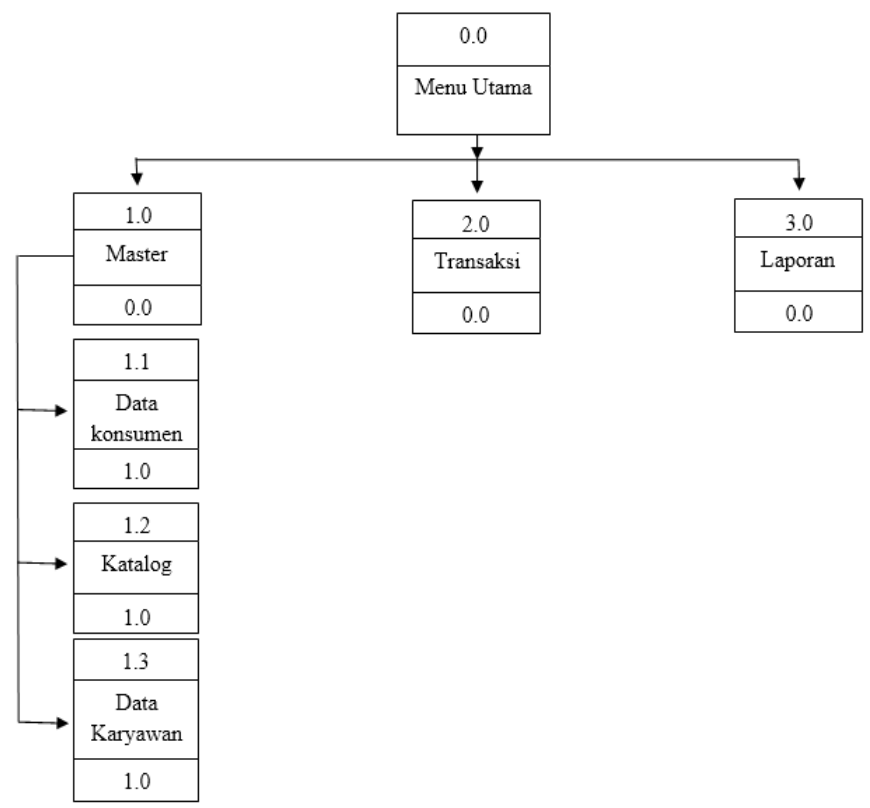

\section{Gambar 5}

\subsection{Spesifikasi Sistem Komputer}

\section{Diagram HIPO (Hierarchy Input Process Output)}

Spesifikasi komputer terdiri dari tiga perangkat, yaitu perangkat keras (Hadware), perangkat lunak (Software).

1) Perangkat Keras

Komponen perangkat keras yang bersifat fisik sebagai berikut:

a. Processor: Intel Celeron DualCore CM1000 $(1.70 \mathrm{GHz})$

b. $\operatorname{Memory}(R A M) \quad: 2 \mathrm{~GB}$

c. Monitor : Monitor dengan resolusi layar minimum $1336 \times 768$

d. Hardisk : $320 \mathrm{~GB}$

e. Mouse : Standart Mouse

f. Keyboard : Standart Keyboard

g. Printer : Inject

2) Perangkat Lunak

Komponen perangkat lunak adalah serangkaian unsur-unsur yang terdiri dari perangkat lunak komputer yang digunakan untuk membantu proses kerja manusia, yang terdiri dari sistem Software dan apllication software. 

a. Sistem Operasi : Microsoft Windows 7
b. Package Program: Microsoft Visual Studio 2012
c. Database : Microsoft Acces 2010
d. Crystal Report : Microsoft Report Viewer

\section{Kesimpulan}

Dengan adanya sistem katalog proses pemesanan lebih terorganisir dan mempermudah dalam prosesnya. Dan mengurangi kesalahan dalam pencatatan ataupun dalam perhitungan sehingga memudahkan admin dalam pembuatan laporan perminggunya.

\section{Referensi}

A, A. I., \& Rangkuti, H. 2008. Perancangan Sistem Informasi Penjualan Tunai PADA PT.KLATEN BERCAHAYA. Jurnal Basic Data,ICT Research Center UNAS Vol.3 No.2 Nopember 2008, 126.

Al-Fatta, Hanif. 2007. Analisa dan perancangan sistem informasi. Yogyakarta: CV. Andi Offset

Darmawan, Deni, Kunkun Nur Fauzi. 2013. Sistem Informasi Manajemen.Bandung: Remaja Rosdakarya.

Fathansyah. 2007. Buku teks Komputer Basis Data. Bandung: Informatika.

Fathansyah. 2012. Basis Data. Bandung: Informatika

Falahi, f. a., alimart, A. k., saputra, D. m., ayunasta, P., \& Simatupang, S.L.2015. Proposal Program Kreativitas Mahasiswa "KONASION" Menumbuhkan Nasionalisme di Kalangan Remaja Melalui Kaos PKM Kewirausahaan. Surakarta: universi (Agus Iskandar, 2008)tas sebelas maret http://scholer.google.com.

Indrajani. 2011. Perancangan Basis Data dalam All ini 1. Jakarta : PT.Elex Media Komputindo.

Komputer, W.2013. Membangun Aplikasi Database dengan Visual Basic 20112. Yogyakarta: CV.Andi Offset.

Mardi. 2011. Sistem Informasi Akuntansi. Bogor: Ghalia Indonesia.

Soemarso. 2007. SistemManajemen Basis Data. Jakarta:Ghalia Indonesia

Sutabri, Tata. 2012. Konsep Sistem Informasi.Yogyakarta : CV. Andi Offset

Simarmata, Janner. 2010. Rekayasa Perangkat Lunak. Yogyakarta: CV. Andi Offset

Yakub. 2012. Pengantar Sistem Informasi. Yogyakarta: Penerbit Graha IImu 